\title{
The day-to-day reliability of peak fat oxidation and $\mathrm{FAT}_{\text {MAX }}$
}

\author{
Oliver J. Chrzanowski-Smith ${ }^{1}$ (D . Robert M. Edinburgh ${ }^{1} \cdot$ Mark P. Thomas $^{1} \cdot$ Nicos Haralabidis $^{1} \cdot$ Sean Williams $^{1}$. \\ James A. Betts ${ }^{1} \cdot$ Javier T. Gonzalez ${ }^{1}$ (D)
}

Received: 23 November 2019 / Accepted: 16 May 2020 / Published online: 1 June 2020

(c) The Author(s) 2020

\begin{abstract}
Purpose Prior studies exploring the reliability of peak fat oxidation (PFO) and the intensity that elicits $\left.\mathrm{PFO}_{(\mathrm{FAT}} \mathrm{MAX}\right)$ are

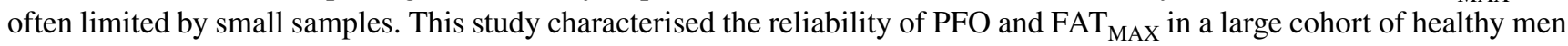
and women.

Methods Ninety-nine adults [49 women; age: 35 (11) years; $\dot{V} \mathrm{O}_{2}$ peak: $42.2(10.3) \mathrm{mL} \cdot \mathrm{kg} \mathrm{BM}^{-1} \cdot \mathrm{min}^{-1}$; mean $\left.(\mathrm{SD})\right] \mathrm{com}-$ pleted two identical exercise tests (7-28 days apart) to determine PFO $\left(\mathrm{g} \cdot \mathrm{min}^{-1}\right)$ and $\mathrm{FAT}_{\mathrm{MAX}}\left(\% \dot{\mathrm{V}} \mathrm{O}_{2}\right.$ peak) by indirect calo-

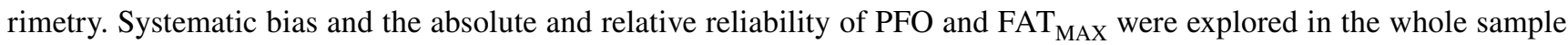
and sub-categories of: cardiorespiratory fitness, biological sex, objectively measured physical activity levels, fat mass index (derived by dual-energy X-ray absorptiometry) and menstrual cycle status.

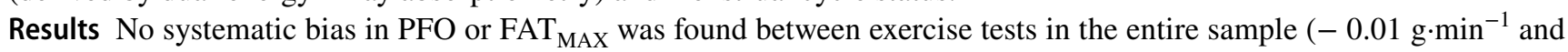
$0 \% \dot{V} \mathrm{O}_{2}$ peak, respectively; $p>0.05$ ). Absolute reliability was poor [within-subject coefficient of variation: $21 \%$ and $26 \%$; typical errors: $\pm 0.06 \mathrm{~g} \cdot \mathrm{min}^{-1}$ and $\times / \div 1.26 \% \dot{V} \mathrm{O}_{2}$ peak; $95 \%$ limits of agreement: $\pm 0.17 \mathrm{~g} \cdot \mathrm{min}^{-1}$ and $\times / \div 1.90 \% \dot{V} \mathrm{O}_{2}$ peak,

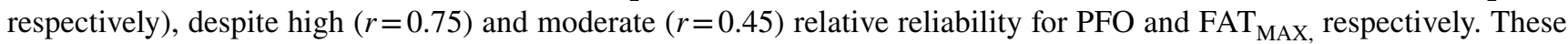
findings were consistent across all sub-groups.
\end{abstract}

Conclusion Repeated assessments are required to more accurately determine PFO and FAT MAX

Keywords Peak fat oxidation $\cdot \mathrm{FAT}_{\mathrm{MAX}} \cdot$ Reliability $\cdot$ Exercise metabolism $\cdot$ Variation $\cdot$ Indirect calorimetry

Communicated by Philip D Chilibeck.

Electronic supplementary material The online version of this article (https://doi.org/10.1007/s00421-020-04397-3) contains supplementary material, which is available to authorized users.

Javier T. Gonzalez

j.t.gonzalez@bath.ac.uk

Oliver J. Chrzanowski-Smith

o.j.chrzanowski-smith@bath.ac.uk

Robert M. Edinburgh

r.m.edinburgh@bath.ac.uk

Mark P. Thomas

m.thomas@bath.ac.uk

Nicos Haralabidis

nh546@bath.ac.uk

Sean Williams

s.williams@bath.ac.uk

James A. Betts

j.betts@bath.ac.uk

1 Department for Health, University of Bath, Bath BA2 7AY,

UK

$\begin{array}{ll}\text { Abbreviations } \\ \text { CVs } & \text { Coefficients of variation } \\ \text { DEXA } & \text { Dual-energy X-ray absorptiometry } \\ \text { ELISA } & \text { Enzyme-linked immunosorbent assay } \\ \text { FAT }_{\text {MAX }} & \text { The intensity that elicits PFO } \\ \text { IUD } & \text { Intraauterine device } \\ \text { IUS } & \text { Intraauterine system } \\ \text { LoAs } & \text { Limit of agreements } \\ \text { MV } & \text { Measured values } \\ \text { NEFA } & \text { Non-esterified fatty acids } \\ \text { P2 } & \text { Second-order polynomial curve } \\ \text { P3 } & \text { Third-order polynomial curve } \\ \text { PFO } & \text { Peak fat oxidation } \\ r & \text { Pearson correlation coefficient } \\ \text { RMR } & \text { Resting metabolic rate } \\ \text { SD } & \text { Standard deviation } \\ \text { SIN } & \text { SINE model } \\ \text { TE } & \text { Typical error } \\ \dot{V} \mathrm{O}_{2} & \text { Oxygen consumption } \\ & \end{array}$

Abbreviations

CVs Coefficients of variation

DEXA Dual-energy X-ray absorptiometry

ELISA Enzyme-linked immunosorbent assay

FAT $_{\text {MAX }}$ The intensity that elicits PFO

IUD Intraauterine device

IUS Intraauterine system

LoAs Limit of agreements

MV Measured values

NEFA Non-esterified fatty acids

P2 Second-order polynomial curve

P3 Third-order polynomial curve

PFO Peak fat oxidation

$r \quad$ Pearson correlation coefficient

RMR Resting metabolic rate

SD Standard deviation

SIN SINE model

$\dot{V} \mathrm{O}_{2} \quad$ Oxygen consumption 


\section{Introduction}

Considerable interest has grown in the concept of peak (or maximal) fat oxidation (PFO; a whole-body measure of the 'maximal' capacity to oxidise fat) and the exercise intensity that elicits PFO (i.e. $\mathrm{FAT}_{\mathrm{MAX}}$ ) (Amaro-Gahete et al. 2019; Maunder et al. 2018). However, knowledge on the reproducibility of these parameters is crucial to be able to appropriately interpret the importance of PFO and FAT $_{\text {MAX }}$ in the context of weight management (Dandanell et al. 2017a, b), metabolic health (Robinson et al. 2015) and/or endurance exercise performance (Frandsen et al. 2017).

Several studies have now investigated the day-to-day reliability (otherwise known as reproducibility, intraindividual variation or within-subject variation) of $\mathrm{PFO}$ and FAT $_{\text {MAX }}$ across a range of exercise modes [e.g. treadmill (De Souza Silveira et al. 2016; Marzouki et al. 2014), cycle ergometry (Croci et al. 2014; Dandanell et al. 2017a, b) and ski ergometry (Hansen et al. 2019)] and populations [e.g. trained or recreationally trained athletes (Croci et al. 2014; De Souza Silveira et al. 2016) and individuals with low levels of cardiorespiratory fitness (Chrzanowski-Smith et al. 2018; Dandanell et al. 2017a, b)]. Notably, in some studies, large intra-individual variation has been reported. For example, Croci et al. (2014) compared the day-to-day reliability of three data analysis approaches to determine PFO and $\mathrm{FAT}_{\mathrm{MAX}}$ [measured values (MV), fitting a third-order polynomial curve (P3) and the SINE model (SIN)] in fifteen moderately trained men and reported large $95 \%$ limits of agreements (95\% LoAs; range $\pm 0.24-0.26 \mathrm{~g} \cdot \mathrm{min}^{-1}$ and $27-32 \% \dot{V} \mathrm{O}_{2}$ peak) and within-subject coefficients of variation $(\mathrm{CVs} ;>15 \%)$ across all approaches. Additionally, similarly large $95 \%$ LoA for PFO $\left( \pm 0.13-0.15 \mathrm{~g} \cdot \mathrm{min}^{-1}\right)$ has been reported in individuals with low levels of cardiorespiratory fitness (Chrzanowski-Smith et al. 2018; Dandanell et al. 2017a, b). However, others report lower CVs $(<10 \%)$ and $95 \%$ LoA $\left( \pm \sim 0.10 \mathrm{~g} \cdot \mathrm{min}^{-1}\right.$ and $8 \% \dot{V} \mathrm{O}_{2}$ peak $)$ for PFO and FAT $_{\text {MAX }}$, respectively (De Souza Silveira et al. 2016; Hansen et al. 2019; Marzouki et al. 2014).

A range of different methods (e.g. gas analysis systems, FAT $_{\text {MAX }}$ protocols, data analysis approaches applied) have been employed to assess PFO and $\mathrm{FAT}_{\mathrm{MAX}}$ that may partly account for such discrepancies in the day-to-day reliability values reported (Amaro-Gahete et al. 2019). Moreover, all prior reliability studies have been conducted in relatively small $(n<23)$ and homogenous samples. Similarly, the only prior study to explore the level of agreement between different data analysis approaches to determine PFO and FAT $_{\text {MAX }}$ recruited thirty-two young, healthy adults (Chenevière et al. 2009). To date, a direct assessment of the day-to-day reliability of PFO and $\mathrm{FAT}_{\mathrm{MAX}}$ across specific sub-populations employing a standardised methodology is yet to be explored but would greatly help to extend the generalisability of prior findings to wider populations.

Therefore, the main aims of this study were to: (1) explore the day-to-day reliability of PFO and FAT $_{\mathrm{MAX}}$ in a large sample of healthy men and women with varying levels of cardiorespiratory fitness, physical activity levels and body composition; (2) investigate whether the day-to-day reliability of PFO and $\mathrm{FAT}_{\text {MAX }}$ is similar across data analysis approaches and sub-populations; and (3) assess the level of agreement between different data analysis approaches [MV, fitting a least squares second-order polynomial curve (P2) and SIN] for determining PFO and $\mathrm{FAT}_{\mathrm{MAX}}$. The hypotheses were that (1) large day-to-day variation would be evident

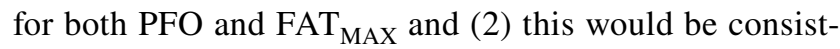
ent across data analysis approaches and sub-populations, alongside (3) higher levels of agreement between P2 and SIN compared to MV.

\section{Materials and methods}

\section{Study design}

This study was a cross-sectional study that involved three visits to the University of Bath, UK. All participants provided written informed consent prior to participating in the study. The study was performed in accordance with the Declaration of Helsinki and was approved by the Research Ethics Approval Committee for Health at the University of Bath (REF: EP 16/17 141) and the South West-Bristol NHS Research Ethics Committee (17/SW/0269) and registered on ClinicalTrials.gov: NCT03029364.

Briefly, participants completed two matched trial days (Trial A and Trial B) separated by 7-28 days that involved the assessment of anthropometrics, resting metabolic rate, a fasting venous blood sample and a $\mathrm{FAT}_{\mathrm{MAX}}$ test. A third visit (Trial C) was also organised 2-7 days after Trial B that involved a dual-energy X-ray absorptiometry (DEXA) scan to assess body composition. Trials were completed after an overnight fast (10-12 h) and started at a similar time ( $\pm 1 \mathrm{~h}$ within participant) of the day (0630-1230 h). Over the 48-h preceding each trial, participants were asked to: (a) abstain from alcohol and strenuous physical activity; and (b) wear a physical activity monitor and replicate their dietary intake and physical activity (all confirmed by verbal questioning). Additionally, over the 7 days before Trial A, participants recorded a self-weighed diet diary and wore a physical activity monitor. On the morning of each trial, participants minimised physical activity and consumed $568 \mathrm{~mL}$ of water upon waking (see accompanying open access readme 
file for study protocol deviances (Chrzanowski-Smith et al. 2020). Participants also maintained their habitual lifestyle throughout their involvement in the study. All trials (within-subject) were performed under similar laboratory conditions [particularly for ambient temperature $(\mathrm{CV}=4 \%)$ and barometric pressure $(\mathrm{CV}=1 \%)$ with more variance in humidity $(\mathrm{CV}=16 \%) ; p$ values for systematic differences between Trial A and Trial B > 0.187] where ad libitum water intake and use of fans were permitted.

\section{Participants}

Ninety-nine healthy male and female adults (aged 18-65 years) were recruited from the South West region of the UK. Exclusion criteria included; age $<18$ or $>65$ years; having current or any history of cardio-pulmonary, metabolic or musculoskeletal disease; breastfeeding or was/potentially pregnant; a body mass index outside of $<18.5$ and $>35 \mathrm{~kg} \cdot \mathrm{m}^{-2}$; not willing to meet the demands of the study or maintain their habitual lifestyle during their involvement; not being weight stable $( \pm 5 \%$ body mass; self-reported) for at least the 3 months prior

Table 1 Participant demographic and lifestyle characteristics

\begin{tabular}{|c|c|c|c|c|}
\hline & Total sample $(n=99)$ & Range & Male $(n=50)$ & Female $(n=49)$ \\
\hline Age (years) & $35(11)$ & $19-63$ & $37(39)^{\dagger}$ & $33(44)^{\dagger}$ \\
\hline Ethnicity (\% Caucasian) & 90 & - & 96 & 83 \\
\hline Body stature $(\mathrm{cm})^{\ddagger}$ & $173.4(8.6)$ & $157.3-191.9$ & $179.6(6.5)$ & $167.0(5.1)$ \\
\hline Body mass $(\mathrm{kg})^{\frac{\ddagger}{\ddagger}}$ & $71.2(11.8)$ & $48.0-106.2$ & $79.5(9.4)$ & $62.8(7.3)$ \\
\hline $\mathrm{BMI}\left(\mathrm{kg} \cdot \mathrm{m}^{-2}\right)^{\ddagger}$ & $23.6(2.8)$ & $18.5-32.9$ & $24.7(2.8)$ & $22.5(2.4)$ \\
\hline Healthy $(n=70,30$ and 40$)$ & $21.9(2.2)$ & $18.5-24.7$ & $23.1(4.8)$ & $21.6(5.9)$ \\
\hline Overweight $(n=27,18,9)$ & $26.6(4.9)$ & $25.0-29.9$ & $26.9(4.9)$ & $26.3(3.5)$ \\
\hline Obese $(n=2,2$ and 0$)$ & $31.8(2.2)$ & $30.7-32.9$ & $31.8(2.2)$ & - \\
\hline Body fat $\% * *$ & $22.5(7.9)$ & $7.7-40.1$ & $17.4(5.6)$ & $27.7(6.3)$ \\
\hline Fat mass $(\mathrm{kg})$ & $15.8(5.6)$ & $5.7-28.8$ & $14.0(5.5)$ & $17.6(5.2)$ \\
\hline Fat mass index $\left(\mathrm{kg} \cdot \mathrm{m}^{-2}\right)^{\ddagger}$ & - & $1.62-10.9$ & $4.5(8.0)^{\dagger}$ & $6.1(7.7)^{\dagger}$ \\
\hline Fat deficient ( $n ; 12$ and 15$)$ & 27 & - & $2.3(1.3)$ & $4.3(1.7)$ \\
\hline Healthy ( $n ; 30$ and 29) & 59 & - & $4.6(2.6)$ & $6.6(3.8)$ \\
\hline Excess adiposity ( $n ; 7$ and 5) & 12 & - & $6.8(2.2)$ & $10.5(1.5)$ \\
\hline Obese $(n ; 1)$ & 1 & - & - & - \\
\hline Fat-free mass (kg) & $54.5(43.5)^{\dagger}$ & $36.4-79.9$ & $64.3(27.9)^{\dagger}$ & $44.9(24.6)^{\dagger}$ \\
\hline Fat-free mass index $\left(\mathrm{kg} \cdot \mathrm{m}^{-2}\right)^{\dagger \neq}$ & $18.24(2.6)$ & $13.3-24.6$ & $20.3(1.8)$ & $16.2(1.27)$ \\
\hline Waist-hip circumference $e^{\neq \dagger}$ & - & $0.67-0.99$ & $0.82(0.13)$ & $.75(0.05)$ \\
\hline Energy intake $\left({\left.\mathrm{kcal} \cdot \mathrm{day}^{-1}\right)}\right.$ & $2365(625)$ & $1235-4852$ & $2724(588)$ & 1999 (416) \\
\hline Carbohydrates $\left(\mathrm{g} \cdot \mathrm{day}^{-1}\right)$ & $245(94)$ & $37-537$ & $285(86)$ & $204(73)$ \\
\hline Fat $\left(\mathrm{g} \cdot \mathrm{day}^{-1}\right)$ & $96(35)$ & $38-212$ & $109(31)$ & $84(35)$ \\
\hline Protein $\left(g \cdot\right.$ day $\left.^{-1}\right)$ & $105(34)$ & $43-221$ & $120(34)$ & $89(27)$ \\
\hline Alcohol $\left(\mathrm{g} \cdot \mathrm{day}^{-1}\right)$ & $4^{\dagger}$ & $0-54$ & $5(54)^{\dagger}$ & $0(24)^{\dagger}$ \\
\hline Physical activity level $(n=96,50,46)$ & $1.72^{\dagger}$ & $1.35-2.42$ & $1.87(1.37-2.42)^{\dagger}$ & $1.57(1.35-2.22)^{\dagger}$ \\
\hline Sedentary $(n=3,1,2)$ & $1.37^{\dagger}$ & $1.35-1.39$ & - & $1.37(1.35-1.39)^{\dagger}$ \\
\hline Low active $(n=29,5,24)$ & $1.52^{\dagger}$ & $1.40-1.59$ & $1.53(1.43-1.59)^{\dagger}$ & $1.52(1.40-1.58)^{\dagger}$ \\
\hline Moderately active $(n=39,21,18)$ & $1.74^{\dagger}$ & $1.60-1.87$ & $1.74(1.61-1.87)^{\dagger}$ & $1.65(1.60-1.87)^{\dagger}$ \\
\hline Very active $(n=25,23,2)$ & $2.03^{\dagger}$ & $1.91-2.42$ & $2.03(1.91-2.42)^{\dagger}$ & $2.08(1.93-2.22)^{\dagger}$ \\
\hline
\end{tabular}

Data presented as mean (SD) unless otherwise stated

$\dagger$ Median (range)

${ }^{\ddagger}$ Average of Trial A and B

$\$$ Derived from Trial C

$\$+$ Average of Trial A and B using DEXA BF\% from Trial C

$B M I=$ body mass index; Fat Mass Index classification derived from Kelly et al. (2009). Physical activity level categories derived from Brooks et al. (2004). No whole sample average data reported for fat mass index and waist-hip circumference, nor fat mass index classifications due to different male and female thresholds. When $n=1$ in a sub-group data not reported 
Table 2 Participant metabolic characteristics and metabolite and hormone concentrations

\begin{tabular}{|c|c|c|c|c|}
\hline & Whole sample & Range & Male & Female \\
\hline$\dot{V} \mathrm{O}_{2}$ peak $\left(\mathrm{L} \cdot \mathrm{min}^{-1} ; n=98,50,48\right)$ & $3.0(0.90)$ & $1.6-5.4$ & $3.7(0.6)$ & $2.3(0.4)^{* * *}$ \\
\hline$\dot{V} \mathrm{O}_{2}$ peak $\left(\mathrm{mL} \cdot \mathrm{kg} \mathrm{BM}^{-1} \cdot \mathrm{min}^{-1}\right)$ & $42.2(10.3)$ & $22.3-65.7$ & $47.3(9.8)$ & $36.8(7.8)^{* * *}$ \\
\hline$\dot{V} \mathrm{O}_{2}$ peak $\left(\mathrm{mL} \cdot \mathrm{kg} \mathrm{FFM}{ }^{-1} \cdot \mathrm{min}^{-1}\right)$ & $54.0(9.6)$ & $33.6-73.0$ & $57.1(9.8)$ & $50.8(8.2)^{* * *}$ \\
\hline Peak power output (W; $n=97,50,47)$ & 230 & $105-434$ & $295(303)$ & $155(198)^{* * *}$ \\
\hline $\mathrm{HR}_{\mathrm{MAX}}$, (beats.min ${ }^{-1} ; n=88,43,45$ ) & $180(10)$ & $148-204$ & $179(11)$ & $181(10)$ \\
\hline PFO $\left(\mathrm{g} \cdot \mathrm{min}^{-1}, n=97,50,47\right)$ & $0.31(0.11)$ & $0.10-0.74$ & $0.35(0.12)$ & $0.28(0.09)^{* * *}$ \\
\hline $\mathrm{PFO}\left(\mathrm{mg} \cdot \mathrm{kg} \mathrm{BM}{ }^{-1} \cdot \mathrm{min}^{-1}\right)$ & $4.45(1.65)$ & $1.55-11.30$ & $4.44(1.68)$ & $4.46(1.63)$ \\
\hline $\mathrm{PFO}\left(\mathrm{mg} \cdot \mathrm{kg} \mathrm{FFM}{ }^{-1} \cdot \mathrm{min}^{-1}\right)$ & $5.72(1.94)$ & $2.17-13.89$ & $5.34(1.83)$ & $6.13(1.98)^{*}$ \\
\hline $\mathrm{FAT}_{\mathrm{MAX}}{ }^{\mathrm{a}}\left(\% \dot{V} \mathrm{O}_{2}\right.$ peak $)$ & $39(10)$ & $21-65$ & $38(12)$ & $40(9)$ \\
\hline NEFA $\left(\mathrm{mmol} \cdot \mathrm{L}^{-1} ; n=79,37,42\right)$ & $0.35^{\dagger}$ & $0.08-1.05$ & $0.31(0.87)^{\dagger}$ & $0.42(0.90)^{\dagger} *$ \\
\hline Triglyceride $\left(\mathrm{mmol} \cdot \mathrm{L}^{-1} ; n=79,37,42\right)$ & $0.64^{\dagger}$ & $0.36-1.51$ & $0.67(1.15)^{\dagger}$ & $0.63(0.76)^{\dagger}$ \\
\hline Glucose $\left(\mathrm{mmol} \cdot \mathrm{L}^{-1} ; n=79,37,42\right)$ & $5.56(0.45)$ & $4.39-6.83$ & $5.72(0.46)$ & $5.37(0.35)^{* * *}$ \\
\hline Lactate $\left(\mathrm{mmol} \cdot \mathrm{L}^{-1} ; n=79,37,42\right)$ & $0.70^{\dagger}$ & $0.43-1.61$ & $0.74(1.16)^{\dagger}$ & $0.59(0.60)^{\dagger} * *$ \\
\hline Insulin $\left(\mathrm{pmol} \cdot \mathrm{L}^{-1} ; n=79,37,42\right)$ & $22.14(5.39)$ & $11.82-40.31$ & $22.83(4.92)$ & $21.35(5.85)$ \\
\hline Oestradiol $\left(\mathrm{mmol} \cdot \mathrm{L}^{-1} ; n=78,41,36\right)$ & $83.7^{\dagger}$ & $18.4-1845.0$ & $68.14(235.7)^{\dagger}$ & $266.8(1826.6)^{\dagger} * * *$ \\
\hline Progesterone $\left(\mathrm{nmol} \cdot \mathrm{L}^{-1} ; n=78,41,36\right)$ & $0.68^{\dagger}$ & $0.22-37.25$ & $0.61(1.15)^{\dagger}$ & $0.79(36.98) \dagger * *$ \\
\hline
\end{tabular}

Data presented as mean $( \pm \mathrm{SD})$ unless otherwise stated below

${ }^{\dagger}$ Median (range); $\dot{V} \mathrm{O}_{2}$ peak = peak oxygen consumption, included in total $n$ is $n=1$ estimated on Trial A and B by Astrand-Rhyming Nomogram (Astrand and Ryhming 1954) and $n=1$ excluded as only completed Trial A; Peak Power Output, $n=2$ excluded as stopped prior to exhaustion $(n=1)$ and did not complete Trial $\mathrm{B}(n=1) ; \mathrm{HR}_{\mathrm{MAX}}=$ maximum recorded heart rate, $n=88$ due to issues with the heart rate monitor; $\mathrm{PFO}$ and FAT $_{\text {MAX }}$, measured values approach, $n=2$ excluded as no metabolic data was available due to hyperventilation in both trials $(n=1)$ and did not complete Trial B $(n=1)$; Metabolites and hormones measured in plasma; NEFA = non-esterified fatty acids; * $p<.05$, female vs male; $* p<0.05$;

$* * p<.01$, female vs male; *** $p \leq .001$, female $v s$ male

to their involvement; or any conditions or concurrent behaviour (including medication) that may have posed undue personal risk to the participant or introduced bias to the study. Participant characteristics are presented in Tables 1 and 2. In female participants who were eumenorrheic and not on contraceptive medication, trials were scheduled (based on self-reported and predicted phases) to take place in the same phase of the menstrual cycle. The menstrual cycle was split into two broad phases: the follicular and the luteal (which included ovulation). The success in controlling for menstrual cycle phase between Trial A and Trial B (based on self-report and predicted phases) was then objectively verified by the analysis of oestradiol and progesterone concentrations. As oestradiol concentrations can vary widely across the menstrual cycle, the follicular and luteal phases were determined by a progesterone concentration of $<$ and $\geq 5 \mathrm{nmol} \cdot \mathrm{L}^{-1}$, respectively (Oosthuyse et al. 2005). As shown in Supplementary Table 1, the success of controlling for menstrual cycle phase was varied. In all females whose menstrual cycle phase was matched between Trial A and Trial B (i.e. were tested in the same phase), testing occurred in the follicular phase (a progesterone concentration of $<5 \mathrm{nmol} \cdot \mathrm{L}^{-1}$ ). If Trial A and Trial B occurred in a different phase of the menstrual cycle, participants were classed as nonmatched. Female participants for whom it was unknown what phase of the menstrual cycle Trial A and/or Trial B occurred in (e.g. progesterone concentrations were not available) were grouped as 'unknown'. Female participants who self-reported the absence of menstrual cycle for $\geq 365$ days were classified as post-menopausal, where low concentrations of oestradiol and progesterone were apparent (Supplementary Table 1). Contraceptive use was categorised into four sub-groups: combined pill, progesterone-only pill, intrarauterine system (IUS) or intrauterine device (IUD).

\section{Anthropometrics}

Anthropometric measurements were performed upon participant arrival at the laboratory. Body stature was measured to the nearest $0.1 \mathrm{~cm}$ using a wall-mounted stadiometer (Holtain Ltd, Pembrokeshire, UK) alongside body mass to the nearest $0.1 \mathrm{~kg}$ using electronic weighing scales (BC543 Monitor, Tanita, Tokyo, Japan). During Trial C, body stature and body mass were assessed in addition to waist and hip circumference [to the nearest $0.1 \mathrm{~cm}$ using a nonelastic measuring tape (SECA 201, Hamburg, Germany)] and a whole-body dual-energy X-ray absorptiometry scan was taken to quantify fat and fat-free mass (Discovery, Hologic, Bedford, UK). 


\section{Blood sample and analysis}

After resting metabolic rate was assessed, a $10-\mathrm{mL}$ whole venous blood sample was obtained from an antecubital vein (BD Vacutainer Safety Lok, BD, USA). Blood samples were equally dispensed into either a 5-mL ethylenediaminetetraacetic acid-coated tube (K3 EDTA, Sarstedt, Germany) or a $10-\mathrm{mL}$ serum/clotting activator tube (Serum Z/10 mL, Sarstedt, Germany) for plasma and serum separation, respectively. Samples for plasma were immediately centrifuged $\left(1700 \mathrm{~g}\right.$ for $15 \mathrm{~min}$ at $4{ }^{\circ} \mathrm{C}$ ); whereas, serum tubes were left to clot for 20-30 min at room temperature prior to centrifugation (standardised within-participant; Heraeus Biofuge Primo R, Kendro Laboratory Products Plc., UK). The plasma and serum samples, alongside the buffy coat layer from the K3 EDTA tube, were dispensed equally into 0.5 -mL aliquots and immediately frozen at $-20^{\circ} \mathrm{C}$, before longer-term storage at $-80^{\circ} \mathrm{C}$ for later batch analysis. The plasma samples were analysed for concentrations of various metabolites and hormones according to manufacturer instructions. Total plasma non-esterified fatty acids (NEFA; Cat No: FA115; intra-assay $<5 \%$ and inter-assay $<5 \%$ ), glucose (Cat No: GL3815; $<5 \%$ and $<6 \%$ ), lactate (Cat No: LC3980; $<4 \%$ and $<5 \%$ ) and triglycerides (Cat No: TR3 $323<4 \%$ and $<4 \%$ ) concentrations were run in singular on a Daytona Rx Series (Randox Laboratories, Crumlin, NI, USA). Total $17 \beta$-oestradiol (Elecsys Estradiol III; $<7 \%$ and $<11 \%$ ) and progesterone (Progesterone III; $<11 \%$ and $<23 \%$ ) concentrations were run in singular on a Cobas 8000 (Modular analytics Cobas e 602, Roche Diagnostics, Rotkreuz, Switzerland). Total plasma insulin concentrations were analysed by an enzyme-linked immunosorbent assay (ELISA) kit in duplicate (Cat No: 900095, Cyrstal Chem, Illinois, USA) with absorption determined by a microplate reader (SPECTROstar Nano, BMG LABTECH, Ortenberg, Germany) at wavelengths specified by the manufacturer (intra-assay $\mathrm{CV}<2 \%$; inter-assay $\mathrm{CV}<24 \%$ ).

\section{FAT $_{\text {MAX }}$ test}

After resting metabolic rate was assessed and a fasting venous blood sample was obtained, participants then completed a $\mathrm{FAT}_{\mathrm{MAX}}$ test. This test adopted a protocol previously validated in individuals who were trained (Achten et al. 2002) and in individuals who had low cardiorespiratory fitness (Chrzanowski-Smith et al. 2018). Briefly, the FAT $_{\text {MAX }}$ test was an incremental graded cycling test to volitional exhaustion completed on a mechanically braked cycle ergometer (Monark Peak Bike Ergomedic 894E, Varberg, Sweden). The graded test comprised of four-min stages for the first seven stages and two-min stages from the eighth stage onwards. The initial power output was $\sim 30$ or $40 \mathrm{~W}$ and increased by $\sim 25 \mathrm{~W}$ (excluding the $10-\mathrm{W}$ increment between first and second stages in the $30-\mathrm{W}$ protocol) over the next five and six stages, respectively, and by $\sim 50 \mathrm{~W}$ from stage seven onwards. One-min expired gas samples, heart rate and RPE were collected in the final min of the first seven stages and upon the participant's signal of one-min remaining before volitional exhaustion. The graded test was used to determine:

a) Peak fat oxidation $\left(\mathrm{g} \cdot \mathrm{min}^{-1}\right)$;

b) FAT $_{\text {MAX }}$ (expressed as a $\%$ of $\dot{V} \mathrm{O}_{2}$ peak);

c) Peak power output (W; power output of the last completed stage, plus the fraction of time in the final noncompleted stage, multiplied by the Watt increment of that stage);

d) An estimate of peak oxygen consumption $\left(\dot{V} \mathrm{O}_{2}\right.$ peak; $\mathrm{mL} \cdot \mathrm{kg}^{-1} \cdot \mathrm{min}^{-1}$ )

Three data analysis approaches were applied to determine

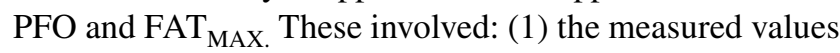
approach [MV; the stage with the highest recorded fat oxidation value and the corresponding $\dot{V} \mathrm{O}_{2}$ (Achten et al. 2002)]; (2) the fitting of a least squares second-order polynomial curve to the measured fat oxidation rates (P2) (Hansen et al. 2019; Stisen et al. 2006); and (3) the Sine model [SIN; a mathematical model that applies a sinusoidal equation to the observed fat oxidation rates and takes into account the dilation, symmetry and translation of the fitted curve (Chenevière et al. 2009). This model estimate was achieved through an excel spreadsheet that involved a solver function kindly provided by Dr Xavier Chenevière].

\section{Metabolic measurements}

Expired gas samples were collected into 100-150 L Douglas bags (Cranlea and Hans Rudolph, Birmingham, UK) via a mouthpiece connected to a two-way, T-shaped nonrebreathing valve (Model 2700, Hans Rudolph Inc, Kansas City, USA) and Falconia tubing (Hans Rudolph Inc, Kansas City, USA). Concentrations of $\mathrm{O}_{2}$ and $\mathrm{CO}_{2}$ were measured in a known volume of each sample via paramagnetic and infrared transducers, respectively (Mini MP 5200, Servomex Group Ltd., Crowborough, East Sussex, UK) and until values were stable. The sensors were calibrated to a two-point low and high calibration of known gas concentrations (low: 99.998\% nitrogen, $0 \% \mathrm{O}_{2}$ and $\mathrm{CO}_{2}$; high: balance nitrogen mix, 20.06\% $\mathrm{O}_{2}, 8.11 \% \mathrm{CO}_{2}$ ) (BOC Industrial Gases, Linde AG, Munich, Germany). Concurrent measurements of inspired air composition were made during collections of expired gas samples to adjust for changes in ambient $\mathrm{O}_{2}$ and $\mathrm{CO}_{2}$ concentrations (Betts and Thompson, 2012). Indirect calorimetry was used to determine: $\dot{V} \mathrm{O}_{2}\left(\mathrm{~L} \cdot \mathrm{min}^{-1}\right) ; \dot{V} \mathrm{CO}_{2}$ $\left(\mathrm{L} \cdot \mathrm{min}^{-1}\right)$; and rate of fat oxidation $\left[\mathrm{g} \cdot \mathrm{min}^{-1}\right.$; estimated by 
Frayn's stoichiometric equations assuming urinary nitrogen excretion was negligible (Frayn, 1983)].

Resting metabolic rate $\left[\left(\mathrm{RMR} ; \mathrm{kcal}^{\left.-\mathrm{day}^{-1}\right)}\right.\right.$ and resting rates of fat oxidation $\left.\left(\mathrm{g} \cdot \mathrm{min}^{-1}\right)\right]$ were measured following guidelines for best practice (Compher et al. 2006): after 15 min of quiet rest in a semi-supine position, RMR was measured by indirect calorimetry of at least two expired gas samples of five-min duration and within $100 \mathrm{kcal} \cdot \mathrm{day}^{-1}$.

\section{Habitual lifestyle assessment}

Habitual physical activity levels were assessed by asking participants to wear a physical activity monitor (Actiheart $^{\mathrm{TM}}$, Cambridge Neurotechnology, Papworth, UK) over the7 days prior to Trial A. Ideally, a minimum of four valid days (monitor worn for $\geq 90 \%$ of time in a day and $<30 \%$ of no heart rate signal) was required to determine habitual physical activity levels (excluding $n=5$ participants for whom only three valid days were available). Additionally, energy expenditure and heart rate values from rest and the FAT $_{\text {MAX }}$ test were entered in the Actiheart ${ }^{\mathrm{TM}}$ software to derive an individually calibrated model estimate of physical activity energy expenditure $\left(\mathrm{kcal} \cdot \mathrm{day}^{-1}\right)$ and mins per day spent in different physical activity thresholds. To assess pre-trial physical activity standardisation, the monitor was also worn for the $48 \mathrm{~h}$ before Trial A and Trial B. Habitual energy and macronutrient intake were assessed by a selfweighed diet diary. Participants were provided with a set of scales (Pro Pocket Scale ${ }_{\text {TOP2KG }}$, Smart Weigh Scales) and asked to keep a written record of their food and fluid intake for at least 4 days in the week preceding Trial A (including at least one weekend day). Additionally, the two days immediately prior to Trial A were recorded, so that participants could replicate this on the two days prior to Trial B. Diet records were analysed using Nutritics software (Nutritics Ltd., Dublin, Ireland).

\section{Statistical analysis}

Assumptions (normality, heteroscedasticity, linearity and proportional bias) for the below statistical tests were explored by a combination of visual inspection (histograms, skewness and kurtosis values and scatter graphs) and quantitative statistical tests (Shapiro-Wilk test, correlations, Levene's test, Mauchly's Test of Sphericity) on raw data and residuals of comparisons. Parametric statistical tests were conducted when assumptions were met with either transformation (natural logarithm followed by anti (inverse)-log to facilitate the interpretation of data in their raw units), or the appropriate non-parametric equivalent was performed. ANOVA models were conducted irrespective of normality due to robustness against violations of normality (Maxwell 1990).
A range of a priori statistical analysis tests were performed to assess the day-to-day reliability of PFO $\left(\mathrm{g} \cdot \mathrm{min}^{-1}\right)$ and $\mathrm{FAT}_{\mathrm{MAX}}\left(\% \dot{\mathrm{V}} \mathrm{O}_{2}\right.$ peak) as advocated (Atkinson and Nevill 1998): (1) systematic bias was assessed by dependent sample $t$ tests and mixed-design analysis of variance (within-subject: Trial A and Trial B; between-subject: group category as per below). Bonferroni-adjusted $p$ values were applied to control for multiple comparisons and for when significant main or interaction effects were detected in the ANOVA models; (2) an index of relative reliability was obtained by bivariate correlation (Pearson correlation coefficient; $r$ ); (3) the absolute day-to-day reliability was investigated by within-subject coefficient of variation $[\mathrm{CV}$; root mean square method(Bland 2006)]; typical error [TE; SD of difference between scores $/ \sqrt{ } 2$ (Hopkins 2015a)]; and Bland-Altman plot with mean difference (bias) and 95\% limits of agreement (LoA) (Bland and Altman 1986). Mean difference was calculated by Trial A minus Trial B; and (4) individual data were plotted on graphs (as shown in Supplementary figures).

These tests were performed on the whole sample and on a range of sub-group analyses:

i. Whole sample $(n=97)$. Systematic bias was assessed by dependent sample $t$ tests. As PFO and FAT MAX were not available for $n=2$ participants in one or both trials (participant fainting and hyperventilation, respectively), these participants were excluded, leaving a maximum sample size of $n=97$.

ii. Data analysis approach (MV, P2 and SIN; $n=72$; $n=34$ females). A two-way repeated measures ANOVA (within subject; Trial: Trial A and Trial B; Model: MV, P2 and SIN) was performed for this analysis. This analysis primarily investigated the day-to-day reliability of each individual data analysis approach rather than the level of agreement between modelling approaches. Mathematical modelling could not be performed for $n=25$ participants due to lack of fat oxidation data points or a plateau in data.

iii. Sex ( $n=50$ males and 47 females). Participants were divided into male and female based on self-report from a participant questionnaire.

iv. Cardiorespiratory fitness $(n=97)$. Participants were categorised into three training classifications (untrained, recreationally trained, highly trained) based on the corresponding $\dot{V} \mathrm{O}_{2}$ peak thresholds outlined for males and females (De Pauw et al. 2013; Decroix et al. 2016). Due to the low sample size $(n=2)$, the highly trained group was excluded from reliability statistics.

v. Fat Mass Index $(n=96)$. Participants were classified into four categories (fat deficient, healthy, excess adiposity and obese) as identified by Kelly et al. (2009). Due to only one participant being classified as obese, 
this individual was excluded from this respective subgroup analysis.

vi. Physical activity level $(n=94)$. Participants were categorised into four physical activity level classifications (sedentary, low active, moderately active, very active) as identified by Brooks et al. (2004). Physical activity data were not available for $n=3$ participants and due to the low sample size $(n=3)$, the sedentary group was excluded from reliability statistics.

vii. Menstrual cycle status and contraceptive use (females only, $n=47$ ). Female participants were divided into seven categories [menstrual cycle matched (Trial A and Trial B occurred in the same phase of the menstrual cycle verified by progesterone concentrations), menstrual cycle non-matched (Trial A and Trial B occurred in different phases of the menstrual cycle phase verified by progesterone concentrations), unknown (eumenorrheic but stage of the menstrual cycle when Trial A and Trial B took place was unknown), contraceptive use combined pill, contraceptive use progesterone-only pill, contraceptive use intrauterine device (IUD), contraceptive use intrauterine system (IUS) and post-menopausal]. Due to the low sample sizes in the progesterone-only pill, IUD, IUS and post-menopausal categories $(n=4,5,3$ and 3 , respectively), these sub-groups were excluded from reliability analyses.

Additionally, the above statistical tests were also employed to explore the level of agreement between the three analysis approaches (MV, P2 and SIN) to determine PFO and $\mathrm{FAT}_{\text {MAX }}$. Estimates of PFO and $\mathrm{FAT}_{\mathrm{MAX}}$ represent the average of Trial A and Trial B, where a one-way ANOVA [within-subject (three levels): MV, P2 and SIN] was used to assess model differences and systematic bias. The sample size for this analysis was $n=72$ ( $n=34$ females).

Log transformation and antilog were required for $\mathrm{FAT}_{\mathrm{MAX}}$ analyses of: (1) whole sample, (2) data analysis approach (reliability of individual models), (3) sex, (4) cardiorespiratory fitness ( $\dot{V} \mathrm{O}_{2}$ peak), and (5) physical activity level. Readers should note that the interpretation of these analyses is distinctly different from when log-transformation was not performed (see Supplementary material 1A for a description). Pearson correlation coefficient, TE and CV were computed for logged data via analysis recommended by Hopkins (2015b). When transformation did not improve the proportional bias (differences plotted against mean) and/or heteroscedasticity (absolute differences plotted against mean) in the data (or consistently across sub-groups), the raw nontransformed data were used for analysis (as such, more caution is required for the interpretation of these results). This was apparent for FAT $_{\mathrm{MAX}}$ analysis of: (1) fat mass index, (2) menstrual cycle status and contraceptive use, and (3) level of agreement between data analysis approaches. Pearson correlation coefficients were interpreted by an $r$ of $<0.40$, $0.40-0.74$ and $\geq 0.75$ for poor, fair to high and excellent, respectively (Dandanell et al. 2017a, b). There is no consensus to date on what constitutes an acceptable level of reproducibility for CVs, TEs or $95 \%$ LoAs for PFO and $\mathrm{FAT}_{\mathrm{MAX}}$. However a mean CV of $8 \%$ and $11 \%$ for the day-to-day reliability of PFO and FAT MAX $_{\text {have been previously stated }}$ as acceptable (Hansen et al. 2019). Additionally, Nordby et al. (2015) and Rosenkilde et al. (2015) report an exercise training-induced increase in $\mathrm{PFO}$ and $\mathrm{FAT}_{\mathrm{MAX}}$ of $\sim 0.13$ to $0.16 \mathrm{~g} \cdot \mathrm{min}^{-1}$ and $5-8 \% \dot{V} \mathrm{O}_{2}$ peak, respectively, compared to non-exercising control groups. Thus, these values were used to help interpret the day-to-day variability values produced for CVs and particularly 95\% LoAs in PFO and $\mathrm{FAT}_{\mathrm{MAX}}$.

Additionally, prior to any of the above analyses, a sensitivity analysis performed in women found that the differences in concentrations of oestradiol and progesterone between Trial A and Trial B did not affect estimates of

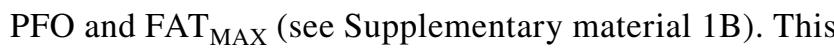
was performed due to the speculation that substrate utilisation during exercise may differ across the menstrual cycle only if concentrations of oestrogen differ by twofold or more between testing occasions (Oosthuyse and Bosch 2010). Consequently, a sensitivity analysis also found no differences in the interpretation of results from menstrual cycle status and contraceptive use when the above statistical tests were performed with and without individuals whose concentrations of oestradiol and progesterone were $\geq$ two- and $<$ twofold between trials, respectively.

Descriptive and statistical analyses were run on Microsoft Excel (2013) and IBM SPSS statistics version 25 for windows (IBM, New York, USA) and graphs were created on Graph Pad Prism 7 software (La Jolla, CA, USA). Data are presented as means \pm SD (or $95 \%$ confidence intervals for $r, \mathrm{CV}$ and TE) unless otherwise stated and statistical significance was accepted at $p \leq 0.05$.

\section{Results}

\section{Day-to-day reliability of PFO and FAT MAX $_{\text {PI }}$}

\section{Whole sample}

No systematic bias was evident between Trial A and Trial B for PFO (Fig. 1a; $p=0.791)$ or $\operatorname{FAT}_{\text {MAX }}(p=0.919$; Fig. 1b). The absolute reliability (TE, CV and 95\% LoAs) of both measures was low (Fig. 1c; Table 3) with high and fair relative reliability $(r)$ for $\mathrm{PFO}$ and $\mathrm{FAT}_{\mathrm{MAX}}$, respectively (Table 3 ). 

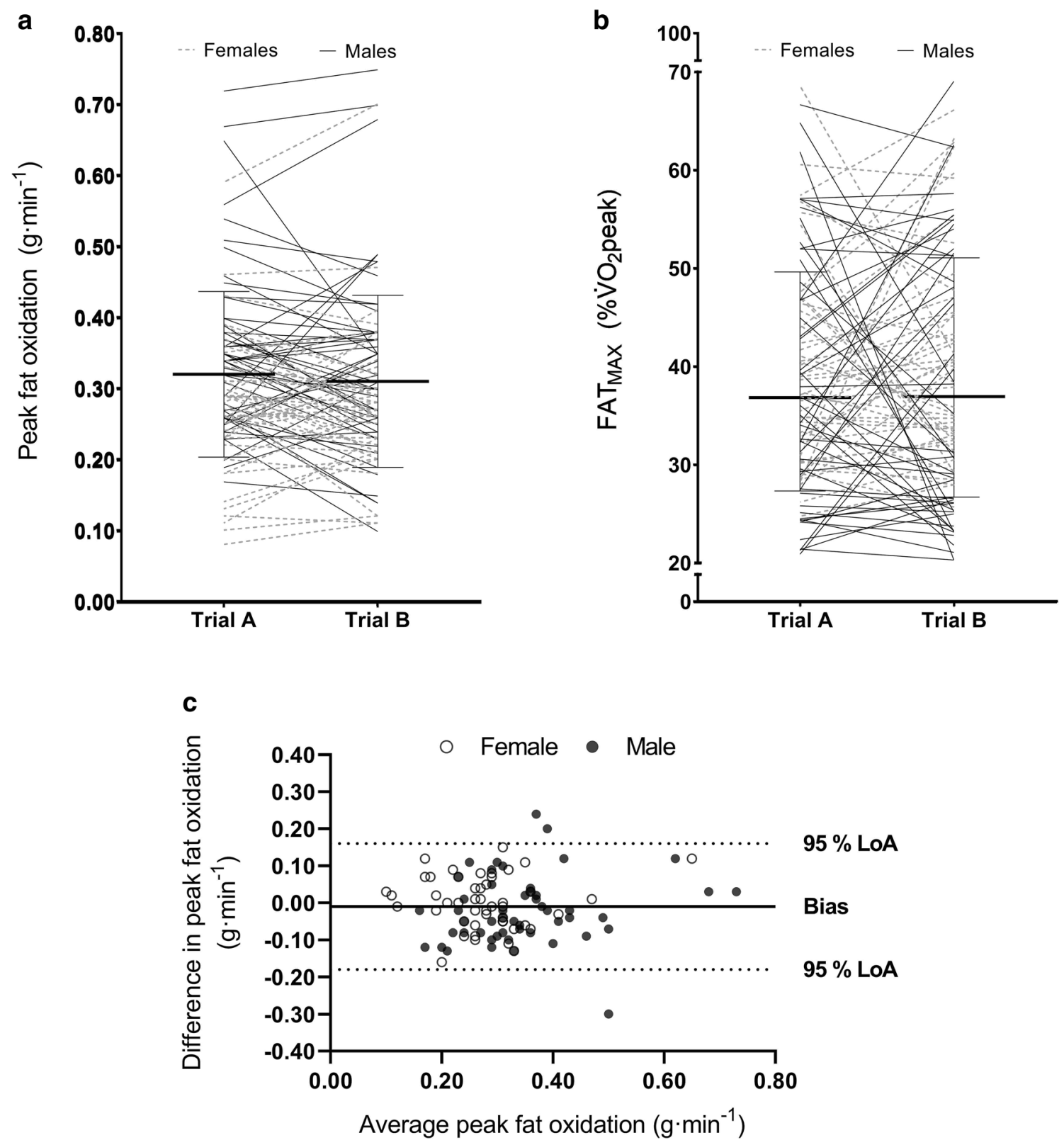

Fig. 1 Comparison of Trial A and Trial B for peak fat oxidation rate $\left(\mathbf{a} ; \mathrm{g} \cdot \mathrm{min}^{-1}\right)$ and $\mathrm{FAT}_{\mathrm{MAX}}\left(\mathbf{b} \% \dot{V} \mathrm{O}_{2}\right.$ peak $)$ in all participants (whole sample). The solid thick line represents mean $\pm \mathrm{SD}$ (or $\times 1 \div$ for $\mathrm{FAT}_{\mathrm{MAX}}$ ) with individual data denoted by the thin lines (dashed =Females; solid=Males). c A Bland-Altman plot display-

\section{Data analysis approach}

A significant main effect of data analysis approach (MV, P2 and SIN) was found for PFO $(p<0.001)$ and FAT $(p=0.001)$. Post hoc tests revealed $\mathrm{P} 2$ produced significantly lower and higher estimates of PFO and $\mathrm{FAT}_{\mathrm{MAX}}$, respectively, at the group level compared to $\mathrm{MV}$ (PFO, $p<0.001$; FAT $_{\text {MAX }} p=0.026$ ) and SIN (both $p$ 's $\leq 0.001$ ) but there were no differences between MV and SIN (PFO, $p=0.653$; ing the difference in PFO $\left(\mathrm{g} \cdot \mathrm{min}^{-1}\right)$ between Trial A and B. The solid line represents bias and the dashed lines represent lower and upper 95\% limits of agreement. Females are denoted by open circles and males are indicated by filled circles. Measured values approach used to determine $\mathrm{PFO}$ and $\mathrm{FAT}_{\mathrm{MAX}}$

FAT $_{\text {MAX }}, p=1.000$ ) (Supplementary Table 2). No main effects of trial ( $p=0.576$ and 0.768$)$ nor trial*data analysis approach interaction effects $(p=0.737$ and 0.767$)$ were apparent for PFO and $\mathrm{FAT}_{\mathrm{MAX}}$, respectively. No systematic bias was evident for PFO ( $p$ values $>0.482$ ) nor for FAT $_{\text {MAX }}$ ( $p$ values $>0.329$ ).

There was large absolute day-to-day variability among all the data analysis approaches for PFO whilst the relative reliability was high (Supplementary Table 2; Supplementary 
Table 3 Whole sample day-to-day reliability in peak fat oxidation and FAT $_{\text {MAX }}$

\begin{tabular}{|c|c|c|c|}
\hline & $\mathrm{A}$ & B & Avg \\
\hline \multicolumn{4}{|c|}{ Peak fat oxidation $\left(\mathrm{g} \cdot \mathrm{min}^{-1} ; n=97\right)$} \\
\hline Mean \pm SD & $0.32 \pm 0.12$ & $0.31 \pm 0.12$ & $0.31 \pm 0.11$ \\
\hline $\mathrm{Bias} \pm \mathrm{SD}\left(\mathrm{g} \cdot \mathrm{min}^{-1}\right)$ & $-0.01 \pm 0.08$ & & \\
\hline$r$ & $0.75(0.65-0.82)$ & & \\
\hline $\mathrm{CV}(\%)$ & $21(17-24)$ & & \\
\hline $\mathrm{TE}\left(\mathrm{g} \cdot \mathrm{min}^{-1}\right)$ & $0.06(0.05-0.07)$ & & \\
\hline $\begin{array}{l}95 \% \operatorname{LoA}( \pm ; \\
\left.\mathrm{g} \cdot \mathrm{min}^{-1}\right)\end{array}$ & 0.17 & & \\
\hline \multicolumn{4}{|l|}{$\operatorname{FAT}_{\mathrm{MAX}}(n=97)$} \\
\hline Mean $\times / \div$ SD & $37 \times / \div 1.35$ & $37 \times / \div 1.38$ & $37 \times / \div 1.30$ \\
\hline Bias ratio & 1.00 & & \\
\hline$r$ & $0.45(0.30-0.57)$ & & \\
\hline $\mathrm{CV}(\%)$ & $26.0(23.0-30.0)$ & & \\
\hline TE ratio & $1.26(1.23-1.30)$ & & \\
\hline $95 \%$ ratio $\operatorname{LoA}(\times / \div)$ & 1.90 & & \\
\hline
\end{tabular}

Peak fat oxidation data presented as mean $( \pm 95 \% \mathrm{CI})$ unless otherwise stated; $\mathrm{A}=$ Trial $\mathrm{A} ; \mathrm{B}=$ Trial $\mathrm{B} ; \mathrm{FAT}_{\mathrm{MAX}}$ data are transformed and presented as mean $(\times / \div 95 \% \mathrm{CI})$ unless otherwise stated

$S D$ standard deviation, Avg Average of Trial A and B (mean \pm SD) ratio, $r$ Pearson correlation, $C V$ within-subject coefficient of variation, $T E$ typical error, $L O A$ limits of agreement, $F A T_{M A X} L O A$ SD ratios

Fig. 2a, 2b and 2c). The absolute day-to-day variability was large for $\mathrm{FAT}_{\mathrm{MAX}}$ across all the data analysis approaches with the MV approach displaying the greatest variation alongside the relative reliability of approaches ranging from fair to high (Supplementary Table2; and Supplementary Fig. 3a, 3b and 3c).

\section{Sex}

A significant main effect of sex was detected for PFO when expressed in absolute terms $\left(\mathrm{g} \cdot \mathrm{min}^{-1} ; p<0.001\right)$ but not for $\operatorname{FAT}_{\text {MAX }}(p=0.070)$ indicating that men had a higher absolute PFO than women $(p<0.001)$. Otherwise, no main effects of trial $(p=0.268$ and 0.931$)$ nor trial*sex interaction effects $(p=0.169$; and 0.353$)$ were found for PFO $\left(\mathrm{g} \cdot \mathrm{min}^{-1}\right)$ and $\mathrm{FAT}_{\mathrm{MAX}}$. No systematic bias was detected in either men $(p=0.380$ and $p=0.603)$ or women $(p=0.743$ and $p=0.373)$ for PFO $\left(\mathrm{g} \cdot \mathrm{min}^{-1}\right)$ and $\mathrm{FAT}_{\mathrm{MAX}}$, respectively (Supplementary Table 3).

The absolute day-to-day reliability in PFO $\left(\mathrm{g} \cdot \mathrm{min}^{-1}\right)$ was poor for both men and women with high relative reliability evident (Supplementary Table 3; Supplementary Fig. 2d). Low day-to-day reliability in FAT $_{\text {MAX }}$ was apparent for both sexes where males displayed slightly greater absolute variation compared to females (Supplementary Table 3;
Supplementary Fig. 3d). The relative reliability of FAT ${ }_{\text {MAX }}$ was fair in both men and women (Supplementary Table 3).

\section{Cardiorespiratory fitness}

A significant main effect of group was found for PFO $(p<0.001)$ but not for $\operatorname{FAT}_{\text {MAX }}(p=0.098)$ showing that trained individuals had a higher PFO compared to untrained individuals (Supplementary Table 4). There was no main effect of trial $(p=0.182$ and 0.866$)$ nor trial ${ }^{*}$ group interaction effects ( $p=0.836$ and 0.229$)$ for PFO and FAT $_{\text {MAX }}$, respectively. No systematic bias was found in untrained $(p=0.297$ and 0.318$)$ or trained individuals $(p=0.395$ and $0.459)$ for PFO and FAT $_{\text {MAX, }}$ respectively.

There was low absolute day-to-day reliability for PFO in both untrained and trained individuals in addition to high relative reliability (Supplementary Table 4; Supplementary Fig. 2e). For FAT MAX $_{\text {, absolute variation was high and was }}$ greater in trained versus untrained individuals (Supplementary Table 4; Supplementary Fig. 3e) with poor and fair relative reliability evident, respectively.

Fat mass index A significant main effect of group was detected for PFO and $\operatorname{FAT}_{\text {MAX }}(p=0.001$ and 0.013 , respectively) indicating that individuals who were fat deficient had a higher PFO and FAT $_{\text {MAX }}$ than individuals classified with healthy levels of adiposity ( $p=0.001$ ) (Supplementary Table 5). There were no main effects of trial ( $p=0.418$ and $0.561)$ nor trial* group interaction effects $(p=0.526$ and 0.268 ) for PFO or $\mathrm{FAT}_{\mathrm{MAX}}$, respectively. There was no evidence of systematic bias across the groups for either PFO ( $p$ values $>0.112$ ) or $\mathrm{FAT}_{\text {MAX }}(p$ values $>0.221)$.

The absolute reliability for PFO showed a slight steplike fashion, whereby individuals classified as fat deficient displayed the highest absolute variability and individuals with excess adiposity showed the lowest, albeit large overlapping of the 95\% CI are evident (Supplementary Table 5; Supplementary Fig. 2f). Alternatively, high to excellent relative reliability was apparent across the FMI classifications (range of $r=0.66-0.81$; Supplementary Table 5). This step-like fashion in estimates of absolute reliability was less apparent for $\mathrm{FAT}_{\text {MAX }}$ with similarly high variation for individuals with healthy and excess adiposity levels which was slightly greater in individuals categorised as fat deficient (Supplementary Table 5; Supplementary Fig. 3f). The relative reliability of FAT $_{\mathrm{MAX}}$ ranged from poor to fair (range of $r=0.19-0.49$ ).

\section{Physical activity level}

A significant main effect of group was apparent for PFO $(p=0.003)$ but not $\operatorname{FAT}_{\text {MAX }}(p=0.130)$ with post hoc tests revealing that individuals with low habitual physical activity levels had a lower PFO than very active individuals $(p=0.002$; 
Supplementary Table 6). No main effects of trial $(p=0.094$ and 0.776$)$ nor trial*group interaction effects $(p=0.929$ and 0.205 ) were found for PFO and FAT ${ }_{M A X}$, respectively. No systematic bias was evident across either of the groups for either PFO ( $p$ values $>0.142$ ) or FAT MAX $_{\text {(all Bonferroni-adjusted } p}$ values $>0.016)$.

Low absolute reliability of PFO was similarly evident across active individuals and those with low levels of habitual physical activity with a slightly higher TE and 95\% LoA apparent in very active individuals (Supplementary Table 6; Supplementary Fig. 2g). The relative reliability for PFO was high across all levels of habitual physical activity level (range 0.73-0.74). Alternatively, greater absolute day-to-day variability for FAT $_{\text {MAX }}$ was apparent in active and very active individuals compared to individuals with low levels of habitual physical activity (Supplementary Table 6; Supplementary Fig. 3 g). Fair relative reliability was evident for FAT MAX $_{1}$ across all habitual physical activity levels (range 0.43-0.57).

\section{Menstrual cycle status and contraceptive use}

No significant main effects of trial ( $p=0.636$ and 0.495$)$, group ( $p=0.385$ and 0.279$)$ nor trial*group interaction effects $(p=0.762$ and 0.184$)$ were apparent for PFO and FAT $_{\text {MAX }}$, respectively (Supplementary Table 7). There was no systematic bias across any of the groups for either PFO ( $p$ values $>0.299$ ) or $\operatorname{FAT}_{\text {MAX }}$ ( $p$ values $>0.090$ ).

Similarly low absolute day-to-day reliability was apparent across all groups for PFO aside for women whose menstrual cycle phase was matched between Trial A and B who displayed a greater CV and 95\% LoA (Supplementary Table 7; Supplementary Fig. 2h). The relative reliability of PFO across all groups ranged from fair to excellent (Supplementary Table 7). The absolute variability between Trial A and $\mathrm{B}$ for $\mathrm{FAT}_{\mathrm{MAX}}$ was similar between women whose menstrual cycle phase was matched or not known, but women who used the combined pill for contraception or whose menstrual cycle phase was not matched between trials displayed lower absolute reliability to a similar magnitude for FAT $_{\text {MAX }}$ (Supplementary Table 7; Supplementary Fig. 3h). Moreover, excellent relative reliability for FAT $_{\text {MAX }}$ was apparent for women whose menstrual cycle phase was matched and for women who were unmatched (or not known) between Trial A and B, with fair and poor relative reliability found for women whose menstrual cycle was not matched or used the combined pill for contraception, respectively (Supplementary Table 7).

\section{Agreement between data analysis approaches}

As identified above, significant main effects of the data analysis approach applied to determine PFO $(p<0.001)$ and $\operatorname{FAT}_{\text {MAX }}(p=0.006)$ were found (Table 4$)$. As FAT MAX $_{\text {M }}$ data were not log-transformed for agreement between data analysis approaches, post hoc tests indicated that $\mathrm{P} 2$ produced slightly higher estimates of FAT $_{\text {MAX }}$ compared to SIN $(p<0.001)$ but not MV $(p=0.692)$. No systematic differences were found between MV and SIN for FAT MAX $_{\text {M }}$ $(p=0.125)$. This was confirmed by dependent sample $t$ tests that found P2 had modestly lower PFO estimates compared to MV and SIN (both $p$ 's $<0.001$ ) and a slightly greater FAT $_{\text {MAX }}$ estimate compared to SIN $(p<0.001)$. Additionally, FAT $_{\text {MAX }}$ was modestly higher with MV versus $\operatorname{SIN}(p=0.042)$.

The absolute agreement between the data analysis approaches to determine PFO was high (as indicated by the low values of CVs, TEs and 95\% LoAs) with excellent relative reliability also evident (Table 4; Fig. 2). The absolute agreement in FAT $\mathrm{MAX}_{\text {Mas }}$ similarly high between data analysis approaches, albeit comparisons involving the MV approach were modestly lower (Table 4; Fig. 2). The relative agreement between all three approaches was excellent FAT $_{\text {MAX }}$ (Table 4).

\section{Discussion}

The main objective of this study was to explore the day-to-day reliability of PFO and FAT $_{\text {MAX }}$ in a diverse sample of healthy men and women. The overall findings were that PFO and FAT $_{\text {MAX }}$ display poor day-to-day reliability in a heterogeneous population of healthy adults, as evident by the reported typical errors $\left( \pm 0.06 \mathrm{~g} \cdot \mathrm{min}^{-1}\right.$ and $\times 1 \div 1.26 \% \dot{V} \mathrm{O}_{2}$ peak, respectively), CVs $(>20 \%)$ and large $95 \% \mathrm{LoA}\left( \pm 0.17 \mathrm{~g} \cdot \mathrm{min}^{-1}\right.$ and $\times / \div 1.90 \% \dot{\mathrm{V}} \mathrm{O}_{2}$ peak, respectively). This large day-to-day variability was apparent despite no evidence of systematic bias for PFO and $\operatorname{FAT}_{\text {MAX }}\left(-0.01 \mathrm{~g} \cdot \mathrm{min}^{-1}\right.$ and $0 \% \dot{V} \mathrm{O}_{2}$ peak, respectively). Moreover, these findings are predominantly independent of sex, cardiorespiratory fitness, fat mass index, physical activity level and menstrual cycle status (and contraceptive use) as similar levels of variability in PFO and FAT MAX were reported across these sub-groups. Additionally, while similar levels of agreement were apparent between the data analysis methods to estimate PFO and $\mathrm{FAT}_{\mathrm{MAX}}$, larger dayto-day variability - particularly in $\mathrm{FAT}_{\mathrm{MAX}}$ - was apparent when the MV data analysis approach was applied.

The day-to-day reliability of PFO and FAT $_{\text {MAX }}$ observed in this study is similar to that reported by some (Croci et al. 2014; Dandanell et al. 2017a, b; Meyer et al. 2009) but not all prior studies (De Souza Silveira et al. 2016; Hansen et al. 2019; Marzouki et al. 2014). For example, Croci et al. (2014) reported large 95\% LoAs (range $\pm 0.24-0.26 \mathrm{~g} \cdot \mathrm{min}^{-1}$ and $27-32 \% \dot{\mathrm{V}} \mathrm{O}_{2}$ peak) and $\mathrm{CVs}$ ( $>15 \%$ ) for both PFO and $\mathrm{FAT}_{\mathrm{MAX}}$ during cycle ergometry across three different data analysis approaches (MV, 
Table 4 Level of agreement between data analysis approaches to determine peak fat oxidation and $\mathrm{FAT}_{\text {MAX }}$

\begin{tabular}{|c|c|c|c|c|c|c|c|c|c|}
\hline & \multicolumn{3}{|l|}{ MV-P2 } & \multicolumn{3}{|l|}{ MV-SIN } & \multicolumn{3}{|l|}{ P2-SIN } \\
\hline & MV & $\mathrm{P} 2$ & Avg & MV & SIN & Avg & $\mathrm{P} 2$ & SIN & Avg \\
\hline \multicolumn{10}{|c|}{ Peak fat oxidation $\left(\mathrm{g} \cdot \mathrm{min}^{-1} ; n=72\right)$} \\
\hline Mean \pm SD & $0.32 \pm 0.10$ & $0.30 \pm 0.10^{* * *}$ & $0.31 \pm 0.10$ & $0.32 \pm 0.10$ & $0.31 \pm 0.10$ & $0.32 \pm 0.10$ & $0.30 \pm 0.10^{* * *}$ & $0.31 \pm 0.10$ & $0.31 \pm 0.10$ \\
\hline $\begin{array}{l}\mathrm{Bias} \pm \mathrm{SD} \\
\left(\mathrm{g} \cdot \mathrm{min}^{-1}\right)\end{array}$ & \multicolumn{3}{|l|}{$-0.02 \pm 0.02^{\S^{*}}$} & \multicolumn{3}{|l|}{$0.00 \pm 0.03$} & \multicolumn{3}{|l|}{$0.01 \pm 0.02^{\S^{*}}$} \\
\hline$R$ & \multicolumn{3}{|l|}{$0.97(0.95-0.98)$} & \multicolumn{3}{|c|}{$0.96(0.93-0.97)$} & \multicolumn{3}{|c|}{$0.97(0.96-0.98)$} \\
\hline $\mathrm{CV}(\%)$ & \multicolumn{3}{|l|}{$7(5-8)$} & \multicolumn{3}{|l|}{$6(3-8)$} & \multicolumn{3}{|l|}{$5(0-8)$} \\
\hline $\mathrm{TE}\left(\mathrm{g} \cdot \mathrm{min}^{-1}\right)$ & \multicolumn{3}{|l|}{$0.02(0.01-0.02)$} & \multicolumn{3}{|c|}{$0.02(0.02-0.02)$} & \multicolumn{3}{|l|}{$0.02(0.01-0.02)$} \\
\hline $\begin{array}{l}95 \% \mathrm{LoA} \\
\quad\left( \pm ; \mathrm{g} \cdot \mathrm{min}^{-1}\right)\end{array}$ & \multicolumn{3}{|l|}{0.05} & \multicolumn{3}{|l|}{0.06} & \multicolumn{3}{|l|}{0.05} \\
\hline \multicolumn{10}{|l|}{$\operatorname{FAT}_{\text {MAX }}(n=72)$} \\
\hline Mean \pm SD & $39 \pm 11$ & $40 \pm 7$ & $39 \pm 8$ & $39 \pm 11$ & $37 \pm 8$ & $38 \pm 8$ & $40 \pm 7$ & $37 \pm 8$ & $39 \pm 8^{\| * * * *}$ \\
\hline $\begin{array}{l}\mathrm{Bias} \pm \mathrm{SD} \\
(\% \dot{\mathrm{V}} \\
\left.\mathrm{O}_{2} \text { peak }\right)\end{array}$ & $1 \pm 7$ & & & $-1 \pm 5$ & & & $-2 \pm 4$ & & \\
\hline$r$ & \multicolumn{3}{|l|}{$0.79(0.68-0.86)$} & \multicolumn{3}{|c|}{$0.87(0.80-0.92)$} & \multicolumn{3}{|c|}{$0.90(0.84-0.93)$} \\
\hline $\mathrm{CV}(\%)$ & \multicolumn{3}{|l|}{$13(10-15)$} & \multicolumn{3}{|l|}{$10(8-12)$} & \multicolumn{3}{|l|}{$9(7-10)$} \\
\hline $\mathrm{TE}\left(\mathrm{g} \cdot \mathrm{min}^{-1}\right)$ & \multicolumn{3}{|l|}{$5(4-6)$} & \multicolumn{3}{|l|}{$4(3-4)$} & \multicolumn{3}{|l|}{$3(2-3)$} \\
\hline $\begin{array}{c}95 \% \text { LoA } \\
( \pm \% \dot{V} \\
\left.\mathrm{O}_{2} \text { peak }\right)\end{array}$ & \multicolumn{3}{|l|}{13} & \multicolumn{3}{|l|}{10} & \multicolumn{3}{|l|}{7} \\
\hline
\end{tabular}

Data presented as mean $( \pm 95 \% \mathrm{CI})$ unless otherwise stated; $n=34$ and 38 females and males, respectively

$A$ Trial A, B Trial B, SD standard deviation, Avg Average of Trial A and B (mean $\pm \mathrm{SD}$ ), $r$ Pearson correlation, CV within-subject coefficient of variation, $T E$ typical error, $L O A$ limits of agreement

$* * * p<.001, \mathrm{P} 2$ vs MV and SIN; ${ }^{{ }^{*}} p<0.001 ; \| * * * p<.001, \mathrm{P} 2$ vs SIN

P3 and SIN) in fifteen recreationally trained males. The present study extends the generalisability of these findings to a large diverse sample of healthy men and women by reporting similar day-to-day variability, particularly for PFO, across the whole sample (MV approach only) and the three data analysis approaches used to determine PFO and FAT $_{\text {MAX }}$ (Supplementary Fig. 2a-c, 3a-c; Supplementary Table 2, respectively). The larger day-to-day variability reported here and by Croci et al. (2014) compared to some previous studies may be due to differences in methodology (e.g. FAT $_{\text {MAX }}$ protocol, gas analysis equipment, data analysis techniques and pre-trial standardisation). Indeed, this study assessed the day-to-day reliability of PFO and FAT $_{\text {MAX }}$ by use of the Douglas bag technique and a Servomex gas analyser which may display different day-today and/or measurement-to-measurement reliability of gas exchange data compared to breath-by-breath gas analysis systems. Accordingly, there is a need for direct comparisons of populations and methods within-studies in order to establish whether these factors predominantly explain the discrepancies between studies.

The present study does suggest though that any differences in the populations recruited by prior PFO reliability studies are not likely significant contributing factors to the differences reported in the day-to-day reliability of PFO and FAT $_{\text {MAX }}$. The relatively large sample size recruited in the present study (maximum $n=97$ for analyses) facilitated various sub-group analyses, allowing direct comparisons of data collected by the same methods. Whilst better day-today reliability was apparent in some sub-groups for both $\mathrm{PFO}$ and $\mathrm{FAT}_{\mathrm{MAX}}$, all sub-groups (excluding females whose menstrual cycle phase was unknown) had quite large $95 \%$ LoAs $\left[> \pm 0.10 \mathrm{~g} \cdot \mathrm{min}^{-1}\right.$ and $10 \% \dot{V} \mathrm{O}_{2}$ peak $($ or $\left.\times / \div 1.46)\right]$, TEs $\left[0.04 \mathrm{~g} \cdot \mathrm{min}^{-1}\right.$ and $8 \% \dot{V} \mathrm{O}_{2}$ peak (or $\left.\left.\times / \div 1.15\right)\right]$ and $\mathrm{CVs}$ $(>13 \%)$ for $\mathrm{PFO}$ and $\mathrm{FAT}_{\mathrm{MAX}}$, respectively. Furthermore, the present study found that controlling for the menstrual cycle phase (objectively verified) and/or contraceptive use through the combined pill had no clear impact on group mean estimates nor the day-to-day reliability of PFO and FAT $_{\text {MAX }}$ (Supplementary Table 7; Supplementary Figs. 2h, $3 \mathrm{~h}$, respectively). From a practical perspective, this suggests that controlling for menstrual cycle phase may not be an important requirement in studies assessing PFO, which is in agreement with recent findings by Frandsen et al. (2020). Thus, more future studies can recruit female participants without using this as justification for their exclusion. This noted, whilst oestradiol is the main circulating form of oestrogen (Mauvais-Jarvis et al. 2013), we did not assess total 


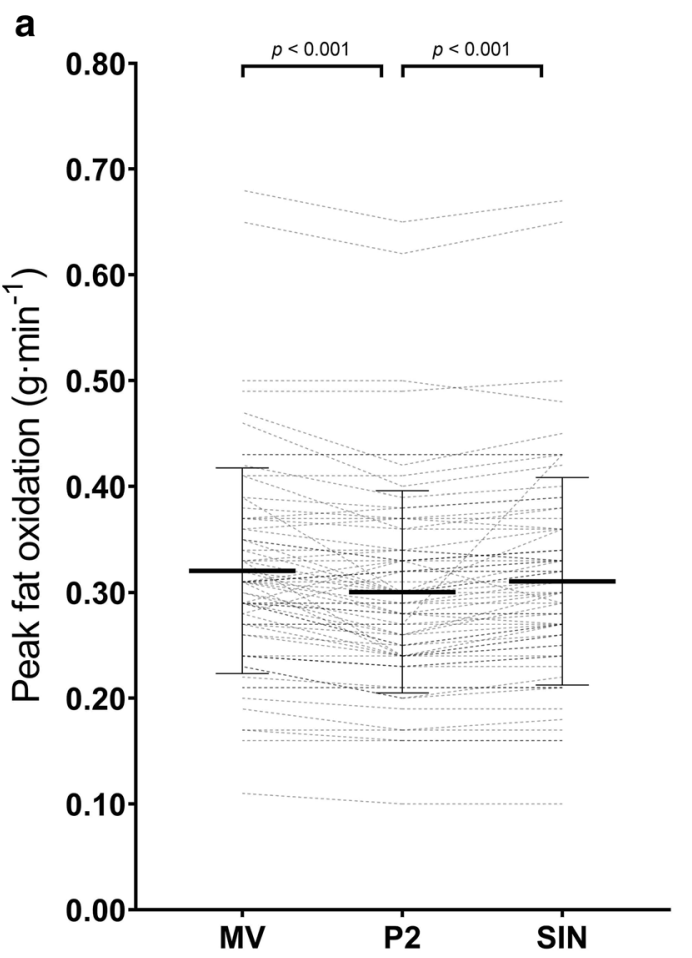

Fig. 2 Comparison of peak fat oxidation $\left(\mathrm{g} \cdot \mathrm{min}^{-1}\right.$; a) and $\mathrm{FAT}_{\mathrm{MAX}}$ $\left(\% \dot{V} \mathrm{O}_{2}\right.$ peak; b) between the different data analysis approaches applied to determine PFO and $\mathrm{FAT}_{\mathrm{MAX}}$ (values reflect an average of

oestrogen concentrations per se. Furthermore, the ratio of oestrogen-to-progesterone may also impact substrate use during exercise (Oosthuyse and Bosch 2010) but was not explored here. Whilst the absence of any systematic bias (e.g. learning effects) in estimates of PFO and $\mathrm{FAT}_{\mathrm{MAX}}$ also suggests there may be no need to perform a familiarisation session prior to the assessment of peak fat oxidation, repeated assessment is still required given the large day-today variation in PFO reported here.

Some caution should be applied in the interpretation of the reproducibility of $\mathrm{FAT}_{\mathrm{MAX}}$ in sub-group analyses. This is because the MV approach, which was adopted to facilitate larger sample sizes for the sub-group analyses, showed lower day-to-day reliability in $\mathrm{FAT}_{\mathrm{MAX}}$ compared to $\mathrm{P} 2$ and SIN (Supplementary Table 2; Supplementary Fig. 3a). This greater variability apparent in FAT $_{\text {MAX }}$ with MV, may arise from the fact that the MV approach can be highly influenced when two or more recorded fat oxidation rates at different exercise intensities provide similar values. In contrast, mathematical models (e.g. P2, P3 and SIN) are largely immune to this issue and thus, are better suited to analysing data that does not form a clear parabolic curve with a distinct peak in fat oxidation rates (Chenevière et al. 2009). Thus, due to their better reproducibility, mathematical models are recommended when the assessment of $\mathrm{FAT}_{\mathrm{MAX}}$ is a key focus.

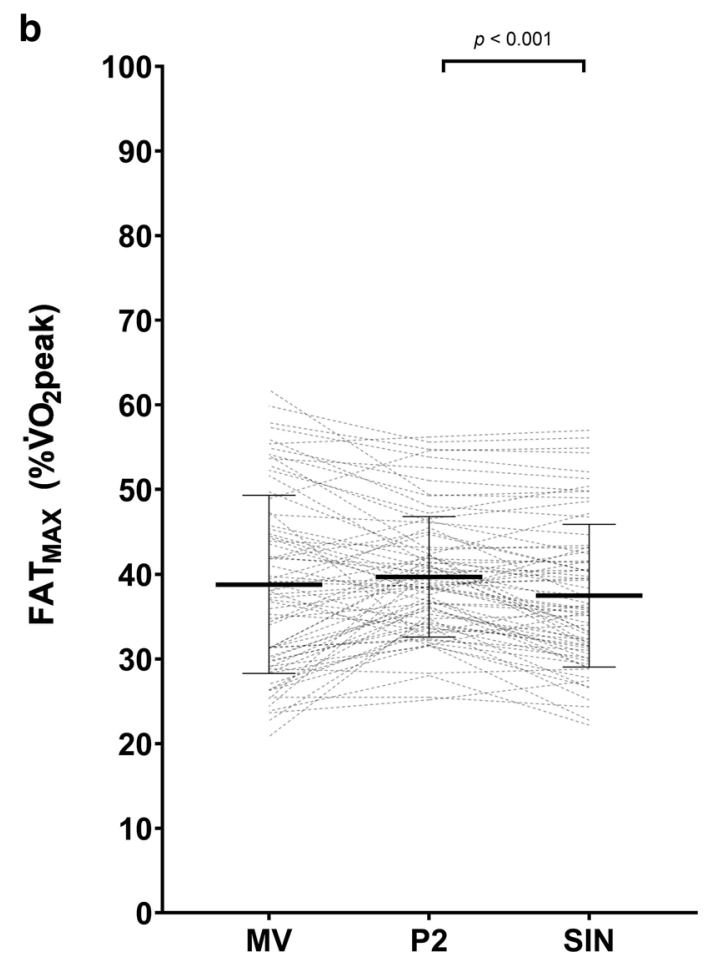

Trial A and Trial B). The solid thick line represents mean \pm SD with individual data denoted by the thin lines

The current study further adds to the literature by reporting similar levels of agreement between the three data analysis approaches that were applied to determine PFO and $\mathrm{FAT}_{\text {MAX }}$ (Table 4). These findings are largely consistent with the only prior study to have also applied the full range of agreement statistics available to investigate this (Chenevière et al. 2009). However, Chenevière et al. (2009) did find higher levels of agreement between P3 and SIN compared to the present study, reporting a mean bias of zero $\left(\sim 0.00 \mathrm{~g} \cdot \mathrm{min}^{-1}\right.$ and $\sim 0 \% \dot{V}$ $\mathrm{O}_{2}$ peak) and extremely narrow limits of agreement $\left(\sim 0.01 \mathrm{~g} \cdot \mathrm{min}^{-1} \sim 2 \% \dot{V} \mathrm{O}_{2}\right.$ peak $)$ for PFO and $\mathrm{FAT}_{\mathrm{MAX}}$, respectively. Additionally, the present study found that P2 and SIN modestly, but systematically underestimated group mean estimates of PFO and $\mathrm{FAT}_{\mathrm{MAX}}$, respectively, when data analysis approaches were compared (Table 4). Interestingly, the direction and magnitude of differences

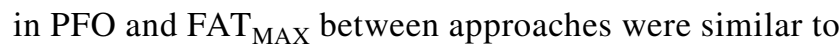
those reported by Chenevière et al. (2009), suggesting that these slight discrepancies may in part be accounted for by the present study being sufficiently powered to statistically detect these differences. Importantly, however, discrepancies do not appear to be an artefact of the polynomial order selected (i.e. P2 versus P3) as no systematic differences in estimates of PFO or $\mathrm{FAT}_{\text {MAX }}$ between P2 
and P3 have been detected (Dandanell et al. 2017a, b). Nonetheless, given the array of data analysis approaches applied in the literature (Amaro-Gahete et al. 2019), the evidence to date collectively suggests that relatively similar estimates of PFO and $\mathrm{FAT}_{\mathrm{MAX}}$ are obtained independent of the data analysis approach applied. Moreover, similar reproducibility particularly when determining PFO appears to be apparent among the most widely used and recommended data analysis approaches (i.e. MV, SIN and polynomial modelling).

The high day-to-day variability in PFO and FAT $_{\text {MAX }}$ reported here and previously (Croci et al. 2014; Dandanell et al. 2017a, b) may partly be accounted for by differences in pre-trial standardisation procedures (Astorino and Schubert 2017). Indeed, fuel selection kinetics during exercise are influenced by many factors, such as immediate nutrient status (Gonzalez et al. 2013), habitual dietary macronutrient composition (Støa et al. 2016) and chronic/ acute physical activity levels (Venables et al. 2005). As per the recommendations (Astorino and Schubert 2017), participants were asked to replicate their dietary intake and physical activity levels, alongside avoiding vigorous physical activity, over the $48 \mathrm{~h}$ prior to each test. The lack of a strict controlled diet in the $48 \mathrm{~h}$ prior to testing in this study may have added to the day-to-day variability of PFO, potentially by altering pre-exercise muscle glycogen levels (Maunder et al. 2018). Equally, whilst this study attempted to objectively verify physical activity standardisation via the wearing of a physical activity monitor, due to data quality issues (e.g. monitor not worn or insufficient data traces), objective verification was not possible for many participants $(n=63)$. In subjects for whom data were available $(n=36)$, no participant replicated their total physical activity energy expenditure $\left(\mathrm{kcal} \cdot \mathrm{day}^{-1}\right)$ or estimated time spent in activity intensity thresholds when an arbitrary threshold of $\pm 10 \%$ of Trial A was set. In addition, only seven participants avoided vigorous physical activity during this period. This demonstrates not only the difficulty of capturing physical activity levels across a short timeframe, but also that self-report confirmation is not sufficient to ensure pre-trial physical activity standardisation (i.e. objective assessment is necessary), which likely contributes to the day-to-day variability in PFO and FAT $_{\text {MAX }}$.

\section{Conclusion}

The present study demonstrates that large day-to-day variability is present when estimating PFO and FAT $_{\text {MAX }}$ in a heterogeneous cohort of healthy men and women. Moreover, this low reproducibility is consistent across sex and different levels of cardiorespiratory fitness, fat mass indices, physical activity levels, and menstrual cycle status and contraceptive use through the combined pill. Nevertheless, there is little-to-no evidence of systematic bias in measures of peak fat oxidation across two identical testing sessions, suggesting there is no need to conduct a familiarisation session. Additionally, the data analysis approach used to estimate PFO and FAT $_{\text {MAX }}$ does not appear to affect reliability estimates particularly for PFO, with similar levels of agreement apparent between the MV, P2 and SIN approaches. Collectively, this suggests that future studies should perform repeated assessments to more accurately determine PFO and $\mathrm{FAT}_{\mathrm{MAX}}$. This will help more precisely prescribe exercise training upon and/or explore the practical relevance of PFO and $\mathrm{FAT}_{\mathrm{MAX}}$ for health and/or endurance exercise performance.

Acknowledgements We would like to thank all participants for graciously volunteering their time and effort to partake in the study. Additionally, Andrea Rawle from the Royal United Hospitals Bath NHS Foundation Trust is thanked for help on the biochemical analysis of oestrogen and progesterone concentrations. Thanks is also sent to Joel Thomas for his help in the study. We would also like to acknowledge funding provided by the University Research Studentship from the Graduate School, Faculty of Humanities and Social Sciences at the University of Bath and the University of Bath Alumni fund. These funds were not involved in any part of the study except for financial and equipment support.

Author contributions OJCS and JTG formulated the idea. OJCS predominately designed the research methodology with input from RME and JTG. OJCS met and recruited all participants, was present on all trial days and collected all experimental data. MPT and RME helped collect data from the exercise tests. OJCS conducted the statistical analysis with assistance from NH and SW. OJCS wrote the manuscript and all authors interpreted, revised and approved the manuscript.

\section{Compliance with ethical standards}

Conflict of interest The authors declare no conflicts of interest. JTG has received research funding and has acted as a consultant for Arla Foods Ingredients, Lucozade Ribena Suntory, Kenniscentrum Suiker and Voeding, and PepsiCo. JAB has received research funding and has acted as a consultant for GlaxoSmithKline, Lucozade Ribena Suntory, Kellogg's, Nestlé, and PepsiCo.

Open Access This article is licensed under a Creative Commons Attribution 4.0 International License, which permits use, sharing, adaptation, distribution and reproduction in any medium or format, as long as you give appropriate credit to the original author(s) and the source, provide a link to the Creative Commons licence, and indicate if changes were made. The images or other third party material in this article are included in the article's Creative Commons licence, unless indicated otherwise in a credit line to the material. If material is not included in the article's Creative Commons licence and your intended use is not permitted by statutory regulation or exceeds the permitted use, you will need to obtain permission directly from the copyright holder. To view a copy of this licence, visit http://creativecommons.org/licenses/by/4.0/. 


\section{References}

Achten J, Gleeson M, Jeukendrup AE (2002) Determination of the exercise intensity that elicits maximal fat oxidation. Med Sci Sports Exerc 34(1):92-97. https://doi.org/10.1097/00005768200201000-00015

Amaro-Gahete FJ, Sanchez-Delgado G, Jurado-Fasoli L, De-la OA, Castillo MJ, Helge JW, Ruiz JR (2019) Assessment of maximal fat oxidation during exercise: a systematic review. Scand J Med Sci Sports 29(7):910-921. https://doi.org/10.1111/sms.13424

Astorino TA, Schubert MM (2017) Changes in fat oxidation in response to various regimes of high intensity interval training (HIIT). Eur J Appl Physiol. https://doi.org/10.1007/s0042 1-017-3756-0

Astrand PO, Ryhming I (1954) A nomogram for calculation of aerobic capacity (physical fitness) from pulse rate during sub-maximal work. J Appl Physiol 7(2):218-221. https://doi.org/10.1152/jappl .1954.7.2.218

Atkinson G, Nevill AM (1998) Statistical methods for assessing measurement error (reliability) in variables relevant to sports medicine. Sports Med 26(4):217-238. https://doi.org/10.2165/00007 256-199826040-00002

Betts JA, Thompson DA (2012) Thinking outside the Bag (Not Necessarily outside the Lab). Med Sci Sports Exerc 44(10):2040-2040. https://doi.org/10.1249/MSS.0b013e318264526f

Bland JM (2006) How should I calculate a within-subject coefficient of variation?. https://www-users.york.ac.uk/ mb55/meas/cv.htm

Bland JM, Altman DG (1986) Statistical methods for assessing agreement between two methods of clinical measurement. Lancet 1(8476):307-310. https://doi.org/10.1016/S0140-6736(86)90837 $-8$

Brooks GA, Butte NF, Rand WM, Flatt J, Caballero B (2004) Chronicle of the Institute of Medicine physical activity recommendation: how a physical activity recommendation came to be among dietary recommendations. Am J Clin Nutr 79(5):921S-930S. https ://doi.org/10.1093/ajen/79.5.921S

Chenevière X, Malatesta D, Peters EM, Borrani F (2009) A mathematical model to describe fat oxidation kinetics during graded exercise. Med Sci Sports Exerc 41(8):1615-1625. https://doi. org/10.1249/MSS.0b013e31819e2f91

Chrzanowski-Smith OJ, Edinburgh RM, Betts JA, Stokes KA, Gonzalez JT (2018) Evaluation of a graded exercise test to determine peak fat oxidation in individuals with low cardiorespiratory fitness. Appl Physiol Nutr Metab. https://doi.org/10.1139/ apnm-2018-0098

Chrzanowski-Smith OJ, Edinburgh RM, Thomas MP, Haralabidis N, Williams S, Betts AJ, Gonzalez JT (2020) Dataset for the dayto-day reliability of peak fat oxidation and FATMAX. Bath Univ Bath Res Data Arch. https://doi.org/10.15125/BATH-00723

Compher C, Frankenfield D, Keim N, Roth-Yousey L, Group EAW (2006) Best practice methods to apply to measurement of resting metabolic rate in adults: a systematic review. J Am Diet Assoc 106(6):881-903. https://doi.org/10.1016/j.jada.2006.02.009

Croci I, Borrani F, Byrne NM, Wood RE, Hickman IJ, Chenevière X, Malatesta D (2014) Reproducibility of fat max and fat oxidation rates during exercise in recreationally trained males. PLoS ONE 9:6. https://doi.org/10.1371/journal.pone.0097930

Dandanell S, Husted K, Amdisen S, Vigels $\emptyset$ A, Dela F, Larsen S, Helge JW (2017a) Influence of maximal fat oxidation on longterm weight loss maintenance in humans. J Appl Physiol (1985). https://doi.org/10.1152/japplphysiol.00270.2017

Dandanell S, Praest CB, Sondergard SD, Skovborg C, Dela F, Larsen S, Helge JW (2017b) Determination of the exercise intensity that elicits maximal fat oxidation in individuals with obesity. Appl
Physiol Nutr Metab 42(4):405-412. https://doi.org/10.1139/ apnm-2016-0518

De Pauw K, Roelands B, Cheung SS, de Geus B, Rietjens G, Meeusen R (2013) Guidelines to classify subject groups in sport-science research. Int J Sports Physiol Perform 8(2):111-122. https://doi. org/10.1123/ijspp.8.2.111

De Souza Silveira R, Carlsohn A, Langen G, Mayer F, ScharhagRosenberger F (2016) Reliability and day-to-day variability of peak fat oxidation during treadmill ergometry. J Int Soc Sports Nutr 13:4. https://doi.org/10.1186/s12970-016-0115-1

Decroix L, De Pauw K, Foster C, Meeusen R (2016) Guidelines to classify female subject groups in sport-science research. Int J Sports Physiol Perform 11(2):204-213. https://doi.org/10.1123/ ijspp.2015-0153

Frandsen J, Vest SD, Larsen S, Dela F, Helge JW (2017) Maximal fat oxidation is related to performance in an ironman triathlon. Int J Sports Med 38(13):975-982. https://doi. org/10.1055/s-0043-117178

Frandsen F, Pistoljevic N, Quesada JP, Amaro-Gahete FJ, Ritz C, Larsen S, Dela F, Helge JW (2020) Menstrual cycle phase do not affect whole-body peak fat oxidation rate during exercise. J Appl Physiol (1985). https://doi.org/10.1152/japplphysiol.00774.2019

Frayn KN (1983) Calculation of substrate oxidation rates in vivo from gaseous exchange. J Appl Physiol Respir Environ Exerc Physiol 55(2):628-634. https://doi.org/10.1152/jappl.1983.55.2.628

Gonzalez JT, Veasey RC, Rumbold PL, Stevenson EJ (2013) Breakfast and exercise contingently affect postprandial metabolism and energy balance in physically active males. Br J Nutr 110(4):721732. https://doi.org/10.1017/S0007114512005582

Hansen MT, Romer T, Frandsen J, Larsen S, Dela F, Helge JW (2019) Determination and validation of peak fat oxidation in endurancetrained men using an upper body graded exercise test. Scand J Med Sci Sports. https://doi.org/10.1111/sms.13519

Hopkins WG (2015a) Measures of reliability in sports medicine and science. Sportscience 19:36-44

Hopkins WG (2015b) Spreadsheets for analysis of validity and reliability. Sportscience 19:36-42

Kelly TL, Wilson KE, Heymsfield SB (2009) Dual energy X-Ray absorptiometry body composition reference values from NHANES. PLoS ONE 4(9):e7038. https://doi.org/10.1371/journ al.pone. 0007038

Marzouki H, Farhani Z, Gmada N, Tabka Z, Shephard RJ, Bouhlel E (2014) Relative and absolute reliability of the crossover and maximum fat oxidation points during treadmill running. Sci Sports 29(6):e107-e114. https://doi.org/10.1016/j.scispo.2014.07.013

Maunder E, DIJ P, Kilding AE (2018) Contextualising maximal fat oxidation during exercise: determinants and normative values. Front Physiol 9:599-599. https://doi.org/10.3389/fphys.2018.00599

Mauvais-Jarvis F, Clegg DJ, Hevener AL (2013) The role of estrogens in control of energy balance and glucose homeostasis. Endocr Rev 34(3):309-338. https://doi.org/10.1210/er.2012-1055

Maxwell SE (1990) Designing experiments and analyzing data: a model comparison perspective. Wadsworth, Belmont

Meyer T, Folz C, Rosenberger F, Kindermann W (2009) The reliability of fatmax. Scand J Med Sci Sports 19(2):213-222. https://doi.org /10.1111/j.1600-0838.2008.00775.x

Nordby P, Rosenkilde M, Ploug T, Westh K, Feigh M, Nielsen NB, Helge JW, Stallknecht B (2015) Independent effects of endurance training and weight loss on peak fat oxidation in moderately overweight men: a randomized controlled trial. J Appl Physiol (1985) 118(7):803-810. https://doi.org/10.1152/japplphysiol.00715.2014

Oosthuyse T, Bosch AN (2010) The effect of the menstrual cycle on exercise metabolism: implications for exercise performance in 
eumenorrhoeic women. Sports Med 40(3):207-227. https://doi. org/10.2165/11317090-000000000-00000

Oosthuyse T, Bosch AN, Jackson S (2005) Cycling time trial performance during different phases of the menstrual cycle. Eur J Appl Physiol 94(3):268-276. https://doi.org/10.1007/s0042 1-005-1324-5

Robinson SL, Hattersley J, Frost GS, Chambers ES, Wallis GA (2015) Maximal fat oxidation during exercise is positively associated with 24-hour fat oxidation and insulin sensitivity in young, healthy men. J Appl Physiol (1985) 118(11):1415-1422. https:// doi.org/10.1152/japplphysiol.00058.2015

Rosenkilde M, Reichkendler MH, Auerbach P, Bonne TC, Sjodin A, Ploug T, Stallknecht BM (2015) Changes in peak fat oxidation in response to different doses of endurance training. Scand J Med Sci Sports 25(1):41-52. https://doi.org/10.1111/sms.12151

Stisen AB, Stougaard O, Langfort J, Helge JW, Sahlin K, Madsen $\mathrm{K}$ (2006) Maximal fat oxidation rates in endurance trained and untrained women. Eur J Appl Physiol 98(5):497-506. https://doi. org/10.1007/s00421-006-0290-x

Støa EM, Nyhus LK, Børresen SC, Nygaard C, Hovet ÅM, BratlandSanda S, Helgerud J, Støren Ø (2016) Day to day variability in fat oxidation and the effect after only 1 day of change in diet composition. Appl Physiol Nutr Metab 41(4):397-404. https:// doi.org/10.1139/apnm-2015-0334

Venables MC, Achten J, Jeukendrup AE (2005) Determinants of fat oxidation during exercise in healthy men and women: a crosssectional study. J Appl Physiol (1985) 98(1):160-167. https://doi. org/10.1152/japplphysiol.00662.2003

Publisher's Note Springer Nature remains neutral with regard to jurisdictional claims in published maps and institutional affiliations. 